\title{
A REVIEW OF SCUFFING AND RUNNING-IN OF LUBRICATED SURFACES, WITH ASPERITIES AND OXIDES IN PERSPECTIVE
}

\section{KENNETH C. LUDEMA}

Mechanical Engineering Department, University of Michigan, Ann Arbor, MI 48109 (U.S.A.)

\section{Summary}

The slow progress in the understanding of scuffing (scoring) and runningin of most lubricated surfaces is probably due to an inadequate understanding of the details of asperity deformation and oxide formation. The thickness and properties of oxides influence the stress states imposed on asperities as much as does the liquid lubricant, but the oxides are ignored in theories. Present theories also focus on adhesion as the cause of scuffing and they usually do not take account of the changing surface roughness during sliding. There may indeed be some evidence of adhesion in the later stages of damage but adhesion has not been demonstrated to be the initiating mechanism of scuffing. Plastic fatigue is the more likely explanation, and this can occur without atomic contact between the sliding surfaces.

\section{Introduction}

\subsection{The practical problem}

The practical problem that gives impetus to the study of running-in and scuffing is the unexpected and catastrophic failure of a few among many otherwise highly successful lubricated sliding components. Such problems occur in gear teeth, piston ring and cylinder pairs, cams and followers, splines and sleeve bearings. There is little agreement on what scuffing is or what its appearance is. Some researchers define scuffing simply as a sudden failure. Some define scuffed surfaces as those that were involved in sudden failure and others describe them as having grooves, adhesion marks, transfer particles and other physical features.

Of the several known mechanisms of wear, scuffing is the least understood. Wear by fatigue, corrosion, abrasion and other slowly progressing mechanisms seems well characterized and regular enough so that designers can predict product life with some confidence. Scuffing and such related phenomena as scoring and galling, however, are not progressive. These topics are often treated somewhat like the yield strength of a material. That is, there is often thought to be a safe regime of operating machinery to prevent 
scuffing, beyond which permanent damage occurs and the machine becomes permanently inoperable. This safe regime is thought to be extended by selecting the proper material, by preparing the surface by a well-controlled process to a safe surface finish, and then subjecting the surfaces to a limited contact pressure, at a limited speed, with adequate lubrication and with proper additives in the lubricant.

One major difficulty for designers is that there are few universal specifications available on how to prevent scuffing of lubricated surfaces. Most designers have access to, or are constrained by, "rules of thumb", most of which result in successful devices and machinery for some present need. However, as technology progresses, the limiting performance of all welldesigned machinery is reached, and new designs become necessary. A frequent practice is to attempt some "fixes" in order to extend the loadcarrying capacity of surfaces. These fixes may include improving the quality control in manufacturing, finding a new lubricant, increasing the stiffness of components in the machine etc. However, fixes are short-term solutions. On a later need to improve the product a new frantic effort is made to find fixes, few of which are built on the wisdom gained in the previous efforts.

There is another common practice that may or may not constitute a fix, i.e. running-in or breaking-in (also bedding-in, wearing-in etc.) a surface before putting the machine in service. Whatever term is used, it has been known for at least 100 years that machinery is likely either to fail early or to last a long time, with few failures at intermediate duration. It is further known that careful operation at the beginning of service will increase the probability of long life. Two practices may be highlighted to distinguish between terms in this area. The first is that sometimes in some machinery it is recommended that hard service be avoided until some time has elapsed in "normal service". In contrast, in other machinery an overt action is taken, such as the use of a special lubricant or the operation of a machine at reduced load or speed for some time, before the machine is placed into normal service. To many designers and users of machinery, running-in consists in "running" a machine under some special, and usually mild, condition for a period of time. The conditions and period are empirically determined because there is little measurable indication of how the sliding surfaces are actually responding to the running-in treatment. However, empirical or not, fixes are often effective and often advance our technology although we do not understand why.

\subsection{Progress in understanding scuffing}

Scuffing is complex indeed, as seen by the fact that many incompatible scuffing theories have been proposed by researchers in several very different disciplines. Unfortunately, in the act of defining scuffing the Organisation for Economic Co-operation and Development group [1] has added to the confusion. Their definition (number 393) is

"localized damage caused by the occurrence of solid-phase welding between sliding surfaces, without local surface melting". 
Doubtless most framers of this definition realize that the failure of a lubricated surface takes place by a progression of events, and one can arbitrarily name several apparent stages toward severe damage. However, the greatest deficiency in the definition is that it implies a progression of welding events from the point of initiation to the point of failure. Lack of clarity on these points may have impeded progress in research on the failure of lubricated surfaces.

Serious studies on scuffing extend backward in time more than 50 years. The most recent large-scale study was reported in 1976 [2 - 4] but these researchers regard their work as clearly unfinished. The late P. M. Ku gave expression to the complexity of scuffing by stating that [5] "a real understanding of scuffing is still not at hand despite so much effort by so many investigators in the past 40 years. It appears that the phenomenological approach has not led us very far, and the time is right for a fundamental analytical approach". This would seem to be a rather sweeping statement were it not for the fact that Ku participated in or led much of the work on scuffing in the U.S.A. over that $\mathbf{4 0}$ years. His was not an isolated view. Two other authoritative works support Ku's appeal for a fundamental approach. The first is a review of scuffing by Dyson [6], who has also worked in the field of lubrication for many years. The second review, by Scott et al. [7], is a very careful analysis of the scuffing of piston rings and cylinder walls of engines. These researchers focus on the struggles to understand the materials aspect of scuffing. The latter review follows on a review of scuffing in engines by Neale [8]. He makes the point that scuffing is, or perhaps partially defines scuffing as, a phenomenon that occurs only in lubricated systems.

Our state of understanding has progressed to the point where a new hypothesis can now be developed. A model is given below, after a short review of the published work in the field. Papers on the subject are of several types but they will here be separated into two groups, namely the phenomenological observations of failing surface and papers that suggest criteria for scuffing failure.

\section{Phenomenological aspects of scuffing}

Scuffing and its prevention are dependent on many variables, such as the duty cycle of machinery, the materials, the methods of preparation of sliding surfaces and the lubricants used in the system. In the sections that follow, these variables are discussed separately, partly to provide a perspective on the state of knowledge in each topic and partly to give references for more detailed study.

\subsection{Effect of materials}

Metallurgists and other materials scientists have made several contributions to the prevention of scuffing of machinery. They have developed a number of specifically "tribological" materials, such as ball-bearing steel, 
cam irons and bushing bronzes. Their work has been largely empirical in nature, and is often based on the simpler laws of wear. Whereas the materials specialist does not give specific rules whereby a scuff-resistant material may be developed, he can often specify a rank ordering of materials in terms of scuff tendency for specific applications. Unfortunately the order is not the same for all applications. For example, for cam followers in engines a composite order of reduced scuff tendency, from several sources, may be found as follows, beginning with the material which scuffs readily:

Babbitt metal $>$ stainless steel $>$ aluminum-killed steel $>$ chilled iron $>$ hardenable nodular iron $>$ hardenable gray iron

For worm gears the order is

soft steel $>$ phenol-formaldehyde-cloth composite $>$ hard steel $>$ bronze

These orders do not correlate with any mechanical property of the material but can sometimes by explained in terms of original microstructure and adhesive properties. In fact, there are three commonly stated criteria for scuff resisting materials, namely the following.

(a) The materials in the two sliding surfaces should not readily adhere together when unprotected by interposing films (a concept sometimes referred to as the compatibility of metal pairs).

(b) Similar materials should not slide against each other.

(c) Two-phase materials are superior to single-phase materials.

The role of surface coatings in scuff prevention should be mentioned also, but a comprehensive view of their effectiveness cannot be given. Hundreds of coatings are available and most of them have not been evaluated. It has been found, however, that porous chromium is better than dense chrome. Nitriding and case carburizing often increase scuffing tendency, and such surface coatings as molybdenum, phosphates, fatty acids etc. are beneficial for the long term. $\mathrm{MoS}_{2}$ and colloidal graphite delay scuffing for a short time.

For a time in the literature some observations were reported of the formation of a "white layer" [7] and a "W2" phase [9] on scuffed surfaces. There has been some attempt to determine whether these are unique metallurgical phases or variants of known phases but the question is unresolved at this time. The appearance of disturbed regions is widely agreed, however.

\subsection{Effect of surface finish}

The most empirical aspect of the design of lubricated sliding surfaces is the specification of the surface finish, both in how the surface is to be produced and the best "roughness number" to be achieved. A large amount of literature exists on surface roughness measurement using the stylus tracer, and there are many papers on the influence of surface finish on the tribological performance of surfaces [10 - 17]. 
Usually the required surface finish (or roughness) shown on design drawings is given in terms of average asperity height, but lately some designers have begun to refer to the more complex features of surface topography in such terms as r.m.s. asperity height, skewness, kurtosis and bearing area. It is interesting to see how often the surface finish (or roughness) is specified numerically in the geometric progression $1,2,4,8,16,32,64$ etc. It would appear that specification in intermediate numbers is either unnecessary, or perhaps designers do not really know what roughness is needed. It is equally interesting to note that in many instances there is an inadvertent secondary specification for surface roughness in the careful specifying of methods to prepare the surface. It is quite likely that more attributes of surfaces are affected by the process than just the roughness. These include three dimensional aspects of topography, residual stress and phase distribution, the combination of which may be referred to as surface condition. There is increasing evidence that the latter attributes may be as important as roughness, and this may explain why two surfaces made by two "reasonably" similar processes, to the same roughness, often perform very differently. One available example is that of the lapping of the connecting rod bearing surface of a crank for a diesel engine. Two cranks were turned and ground in the same way. One was lapped in the same direction of crank rotation as occurred during grinding. The other was lapped in the opposite direction, and both were finished to an $18 \mu$ in center-line average (c.l.a.) roughness. In engine tests there was a ratio of $8: 1$ in half-shell bearing life with these two cranks. The roughness number alone was obviously inadequate to characterize these surfaces for functioning as bearings at least.

The roughness of a surface is sometimes treated as an invariant profile in tribological literature, particularly by those that propose failure criteria. Measurements show, however, that roughness changes considerably in the first seconds or minutes of operation of "concentrated contacts" [18-21]. Furthermore, the change for surfaces that are progressing to early failure is noticeably different from that for surfaces that last a long time, and the changes depend on the original surface condition [22]. There are three explanations often given.

(a) A glaze may be formed [23], consisting of $\mathrm{Fe}_{3} \mathrm{O}_{4}$ and carbon, as on engine cylinder walls, and this glaze may prevent scuffing.

(b) Asperity tops may be "worn off" to provide flat contact regions. This simple concept begs the question of the details of the wearing off of the tops of asperities. A typical paper on this subject [24] reports the flattening of asperities which were originally of a $0.48 \mu \mathrm{m}$ c.l.a. roughness, but $2.1 \mu \mathrm{m}$ of material was worn away before the flat tops were seen! This was on the cylinder walls of a 6 h.p. engine. One could conclude from the results that the action of piston rings is to develop asperities which are flatter than those formed by honing, but not that the original asperities were flattened.

(c) Sreenath and Raman [24] also suggest that debris may fill valleys, which also causes some smoothing. There is no comment offered on why loose debris becomes so firmly attached to the valleys. 
It should be noted that a distinction is made here between the effect of certain details of surface roughness on scuff prevention and the effect of surface roughness on wear rate. On the latter, for example, one paper [10] reports that lubricated wear is more sensitive to orientation of surface "lay" for rougher surfaces.

\subsection{Effect of operating cycles of machinery}

One of the complications in scuffing is that the probability of scuffing is not always the result of a simple addition of overloads or oil starvation that sliding surfaces may be subjected to. There is a strong "healing" effect when an overload is removed, which implies that the temporal spacing of overload may be important. Another observation is that two surfaces that contact each other exclusively are more prone to scuff than if either or both also contact other surfaces. This is seen in gear teeth that contact each other regularly such as on gear wheels with ratios of $1: 1$ or $1: 2$ and in rollers with a fixed slide-roll ratio when connected by gears rather than when operated independently by electric motors. Reasons have not been found.

\section{Scuffing criteria}

\subsection{General considerations}

Lubrication prevents early failure of sliding surfaces in high speed and high load service. Liquid lubricants serve mostly to distribute some or all of the contact load over the entire nominal area rather than upon widely separated asperities, and they reduce asperity heating when contact occurs. A second function of the lubricant is to remove some of the heat from regions on the solid surface that may have been deformed and heated. Failure then is suggested by some to involve the loss of either or both functions of the lubricant.

\subsection{The elastohydrodynamics approach}

The condition for adequate (fluid film) lubrication may be calculated approximately with the equations of elastohydrodynamics (EHD). The main practical goal of EHD is to calculate the minimum film thickness $h_{0}$ of the lubricant between solid surfaces. If the fluid film thickness can be maintained to a dimension greater than that of asperity heights on the sliding surfaces, there should be no scuffing [25]. The ratio of film thickness to effective or composite surface roughness is designated $\Lambda$. Intuitively, it would appear that $\Lambda$ should be greater than 1 and should not depend on other factors. Tests show, however, that the critical value of $\Lambda$ is different for at least three classes of parts as shown in Table 1 [26]. Thus it is seen that there is no single exact critical value for $\Lambda$ and it probably is influenced by lubricant chemistry as well as materials and surface condition. 
TABLE 1

Critical values of $\Lambda$

\begin{tabular}{ll}
\hline Application & Critical $\Lambda$ (derived from experience) \\
\hline Rolling element bearings & $1-2.5$ \\
Gears & $0.5-1.7$ \\
Cams & $0.25-1$ \\
\hline
\end{tabular}

The calculation of $h_{0}$ has traditionally been performed with the assumption of laminar flow of fluid, on perfectly smooth surfaces and with a single substance, namely the lubricant only with no consideration of surface active species. Recent research has concentrated on a more precise analysis of the pressures and flow patterns in the entrance region of sliding bodies and on exact rheological properties of lubricants in the contact region.

The influence of surface roughness is also under investigation but is beset by several difficulties. These include the following.

(a) In analysis, when $h_{0}$ approaches the dimensions of the height of asperities it is necessary to modify the equations of EHD to accommodate the influence of asperities on lubricant flow. Real asperities are difficult to represent accurately in EHD equations so arrays of spheres and sinusoidal ridges are assumed.

(b) In experimental work it has not been possible to detect the first contact of asperities unambiguously. Thus one cannot verify the theories.

(c) It is not obvious that "asperity contact" is to be avoided. (Contact is sometime taken to mean metallurgical contact, and it is sometimes taken to mean a "load transfer" event or interaction.) Many successful sliding surfaces change microcontours considerably during operation, implying frequent and continuing asperity interaction. For example, the widely used test devices for evaluating lubricants operate in a mode in which the electrical resistance across the contact region is less than $0.001 \Omega$ and there is severe distortion of hardened steel asperities during the test, but the surfaces often survive for many hours.

\subsection{Adsorbed films}

The general tribological influence of physically and chemically adsorbed films on metals was well known in 1950 [27]. Little progress has been made since in developing a detailed model of film behavior. Very recently antiwear additives were still thought to "act by forming a protective coating on the rubbing surfaces" [28]. No one has published the details of the mechanism of this protection.

Since the goal of this paper is to explore the physical behavior of surface films, there will not be an extensive review of the competent work in additive chemistry. It is apparent, however, that there may be several films on a surface, each with different properties, some synergistic and some not. 
The physically adsorbed films should be the simplest to understand in that they do not form new compounds. Additives containing oxygen, chlorine, sulfur and phosphorus, in contrast, form new compounds on iron surfaces when the conditions for reaction are proper. Each reaction for each compound takes place at different ratcs and there is a competition between additives [29]. The optimization of additive combinations for each metal and for each type of service requires considerable skill. For the reactive species a high reaction rate followed by fast removal of the products of reaction causes a high wear rate but seems to prevent scuffing. A low reaction rate, however, will allow scuffing. There is, therefore, a proper balance of reactions. Safe practice consists in avoiding the catastrophic and unpredictable scuffing of surfaces and this is achieved by increasing the reactivity of additives, which in turn favors chemically enhanced wear. The latter has the single advantage of being predictable and progressive.

\subsection{Thermal theories of scuff initiation}

In all discussions of scuffing it appears to be assumed that an adequate supply of clean and properly formulated lubricant exists. Scuffing is then explained on the basis of the energy density in the conjunction between sliding surfaces, i.e. high load and/or high speed produces high temperatures on surfaces which, when high enough, produce scuffing [30-36]. There is little consensus, however, on what temperatures are achieved or on the details of scuff initiation. There are at least four hypotheses on the latter, including the following.

(a) The first is fluid film thinning [37], which is usually thought to occur in the vicinity of asperities where locally higher pressures and fluid shear rates should exist. The fluid in that region heats up, the viscosity of the fluid decreases, which produces a thinner fluid film in which a higher concentration of shear energy exists to heat the fluid at a higher rate etc., resulting in "collapse". No convincing analytical models are available which are based on the above hypothesis.

(b) The second is lubricant desorption: this is usually discussed in relation to liquid lubricants containing surface-adsorbing additives [28, 38, 39] but in principle is equally applicable to base oil. The adsorbed species are said to detach (desorb) when a particular temperature (about $150^{\circ} \mathrm{C}$ ) is reached. The concept of a temperature-activated desorption seems to be less in question than the particular temperature at which it is said to occur.

(c) The third hypothesis involves asperity expansion [40, 41]. As one asperity on one surface passes close to several asperities on the countersurface, the single asperity heats up (by an unspecified mechanism) and expands. It then stands above its previous height, exposing it to still closer passage of more asperities, causing more thermal expansion etc. If the summit of the expanded asperity is progressively removed, the rate of heating decreases, which begins a cooling trend, which results in contraction etc. As the first asperity is cooling, another asperity begins to heat and follows the same cycle. This sequence of events is well verified in experiments 
where metal pins slide on glass. Hot spots are seen to "dance around" within the contact region.

If an expanded asperity does not wear away, it may adhere to another, initiating scuffing. No experimental proof of the validity of this hypothesis has come to light.

(d) The wettability of liquids in heated regions may decrease, causing starvation of lubricant [42].

(e) "Soft-solid" surface films, which were formed by chemical reaction of additives in lubricants with metal and/or metal oxide, may melt. When the film melts, its effectiveness in reducing metal-metal contact is reduced considerably.

\section{Probable mechanisms of scuffing}

The failure of a lubricated surface is a complex series or continuum of events. The entire sequence probably does not occur in exactly the same way on all surfaces and on all materials. There is no term that serves better as a name for the sequence than scuffing, but the term must be redefined. It is here defined in terms of the microscopic aspects of surface failure. Perhaps this leaves the term "scoring" for the macroscopic manifestations of failure.

\subsection{A definition of and a model for scuffing}

The above definitions and descriptions of scuffing are very limiting, seeming to refer exclusively to the advanced stages of a phenomenon that must have originated on a very small scale. A more general definition is here given as

"a roughening of surfaces by plastic flow whether or not there is material loss or transfer".

By this definition, scuffing is not limited to high severity of damage or severe wear loss such as is often seen in a four-ball machine, but it is described as beginning on the scale of a single asperity and extending to any point of macroscopic manifestation up to seizure.

The initiation of scuffing is not here defined as requiring an adhesive action in the classic sense of adhesion or welding. The invoking of adhesion is an unnecessary extrapolation of an observation from the advanced stage of surface damage to the initiating stage. In fact, there is insufficient evidence that a metallurgical bond has bridged the sliding interface in early stages, even though the electrical conductivity across the interface may have been high. There are, for example, other reasons for high electrical conductivity than adhesion of metals, such as the existence of conducting particles between surfaces or electronic tunnelling through very thin surface films.

The initiation of scuffing is here assumed to begin by the plastic flow of one asperity, and this is inferred by extension backward from the grosser plastic flow seen in later stages of scuffing. Plastic flow of asperities occurs 
by some combination of normal and tractive stresses, both of which can be transmitted through interposing films whether viscous or (soft) solid.

Scuffing then progresses by continued and repeated plastic flow of some asperities. After a few tens or hundreds of cycles of sufficient plastic flow some deformed asperities break away by plastic fatigue [43]. These debris particles agglomerate to form larger particles, which are repeatedly deformed and work hardened as they pass through the contact region. Eventually, a larger particle carries most of the load of the "contact" region, which produces a contact stress too large to sustain fluid film lubrication. Temperatures rise precipitously, which chemically alters any remaining protective films in the interfaces, and welding or adhesion occurs. The latter produces further severe plastic flow and heating, which propagates the damage at an ever-increasing rate.

\subsection{Running-in and scuff quenching}

The progression toward surface failure can be interrupted at any point. The plastic flow of asperities may be stopped at some point by the development of a surface film that reduces the shear stress. This may occur by a change in asperity shape such that local fluid films are no longer thinned excessively. Alternatively, this may occur by the formation of an adsorbed chemical species that has a low shear strength. The result would be the interruption of the progression toward plastic fatigue of asperities.

At a later stage the progression toward scuffing may be interrupted by quick disposal of debris particles. This would be a matter of fluid flow, the extent of repeated sliding of local areas of surfaces and the shapes of the load-carrying contact regions. It is also possible that the mechanical properties of the debris are important, such as the ductility and work hardening properties.

At a still later stage, scuffing may be forestalled by insertion or formation of chemical compounds at the interfaces that either decompose at a very high temperature or produce decomposition products that are soft and ductile.

In terms of the emphasis on mechanisms in this paper, running-in may be defined as the healing of a microscuff. Alternatively, running-in could be called "scuff quenching". This extends the definition of scuffing to a microscale in distinction from the gross damage scale stated above. If microscuffing advances to macroscuffing, then the function of the machine may be compromised. If microscuffing is quenched, or if by some negative feedback mechanism microscuffing is halted, then running-in has been accomplished.

The above model is very general but it does emphasize the need for better understanding of at least two mechanical mechanisms involved in scuffing. The first is an understanding of the details of plastic flow of asperities. This will depend on a number of factors, including the shapes and mechanical properties of and the loads on asperities.

The second is the thickness and mechanical properties of adsorbed films on surfaces. The films control or limit the normal and shear stresses that will 
be applied to asperities during sliding. There are many types of films, depending on the chemistry of the lubricants. One type of film, however, is present on all ferrous metal surfaces operated in air. These are the iron oxides, and they will be discussed in Section 5 .

\section{Oxygen and oxides}

\subsection{The role of oxygen}

Oxygen apparently plays a role different from that of the other wearcontrolling additives in oil. This difference is chiefly due to the ubiquitous nature of oxygen. It is usually not added deliberately but, when it is deliberately excluded, it is found to have had an effect [44]. Dyson states that "scuffing is dominated by lack of oxygen at low partial pressure with chemically inert lubricants". Water vapor apparently behaves in the same way as oxygen does [45] and both have been identified as specifically causing chemically enhanced wear [46].

Several researchers speculate that the effectiveness of oxygen in nonadditive oil is due to the formation of a "friction polymer" [46] or a "carbonaceous debris" $[44,47,48]$. An interesting note on films is that they are sometimes soluble in the liquid phase of the oil. A discussion in ref. 49 states that, in straight mineral oil, a low friction film is formed during a test which dissolves off when the (disc) machine is idle for $1 \mathrm{~h}$. "Scoring always arises on reaching the conditions at which the break (in the test) was made, unless the running-in procedure is repeated in full."

Oxygen may have some influence on the action of other additives. Some workers assert that air is not required if other additives are available, and it may interfere with the action of other additives. Other researchers reply that oxygen is always useful but only a minute concentration is required [46] and its influence may be seen in the formation of oxide debris [29]. In some instances, oxygen is seen to retard the action of other extreme pressure additives $[50]$.

A final view to be reported from the literature is that the chief role of oxygen is to produce oxide and that "irrespective of the initial lubrication condition, oxidation of the steel surfaces leads to low friction and mild wear" [51]. It is a practical fact that oxide alone is not sufficient since most systems in which there is high contact stress use reactive additives in lubricants. To repeat, it is known that the effectiveness of oxide is clearly shown in non-reactive oil, but no work has been found in which the relative merits of extreme pressure films over oxide films are reported. It is the intent of this paper to suggest criteria for measuring such effectiveness, perhaps in such terms as tenacity or shear strength of films and layers. It is possible that extreme pressure films provide effective protection most of the time whereas the oxides may provide the final protection in extreme cases. Thus, there may be some evidence that extreme pressure films can function without oxide but, as a practical matter, oxides are present in most systems and 
therefore must be taken into account. Finally, it must also be stated in this connection that, if scuff initiation takes place on a microscopic scale, then all microscopic entities must be thoroughly characterized, including the oxides.

\subsection{The nature and function of oxides in wear and scuffing}

The role of oxides in lubricated systems seems to parallel that found in unlubricated systems. There it is found that surfaces may wear away in a regular and progressive mode without a catastrophic event. Even in lubricated systems, the wearing away of materials may occur in increments on a scale less than $50 \AA$, which is the order of the thickness of oxide films. That oxides are present and effective in scuff prevention in lubricated systems is demonstrated in several papers $[6,52]$. These works follow the style of work of the last 30 years in the topic that has become known as oxidative wear. A sliding pair is operated over a wide range of sliding speeds and loads in various gaseous environments [53-57]. The rate of wear is measured for each condition of operation and the wear debris is chemically analyzed. It is found that, when oxygen is absent, high wear and high friction occur and the wear debris is metallic. When oxygen is present, wear is very much lower, friction is significantly lower and the wear debris is mostly oxide.

Several researchers have reported work on the specific role of oxides in dry wear, but usually from the point of view of the rate of growth of oxides in various environments [58-62]. Bjerk [49] is the first, and perhaps the only so far, researcher who directly connected scuffing resistance with the presence of oxides in the contact zone. He conducted a test using a gearedroller test machine. The test results with mineral oil as the lubricant were compared using two different atmospheric conditions, one a nitrogen atmosphere and the other air. The results of the test show that the roller surface was scuffed in nitrogen but was not scuffed in air. Bjerk measured the chemical content of surface layers of the rollers using a microprobe analyzer. For the rollers tested in nitrogen, the microprobe indicated $5 \mathrm{wt} . \% \mathrm{O}$ in an undamaged region of the contact track and about $3 \mathrm{wt} . \% \mathrm{O}$ in the scuffed regions. For the rollers tested in air, the oxygen content was about $8 \mathrm{wt} . \%$ in the scuffed region of track. Bjerk concluded that, because the undamaged track exhibits a higher amount of oxygen, a scuff-resistant layer is rich in oxides. He also stated that since there was an insignificant increase in carbon in the undamaged track, the possibility that the scuffing resistance was due to a build-up of "friction polymer" alone must be ruled out.

\subsection{Research topics on oxides}

Oxides will inevitably form on lubricated ferrous surfaces operated in air [63]. A complete modeling of scuffing therefore would require some information on the thickness and mechanical properties of the three oxides that form on iron. In addition, the details of the adsorption of active chemical species (other than oxygen) in the oil onto oxide should be better understood. 
A practical reason for understanding the role of oxides is to develop ways to process surfaces so that scuffing may be prevented in the early life of a machine, thus avoiding the running-in step. This may involve the deliberate formation of given oxide films, formed upon a very specific surface topography.

In very general terms the oxides should have the following properties.

(a) They should enhance the adsorption of select species from the supplied lubricant.

(b) The oxide films on contacting surfaces should transfer less shear stress when in contact with each other than would the substrate metals. This condition might be fulfilled by effecting one or more of the following.

(1) A very ductile and soft oxide can be formed to accommodate a plastically deforming substrate and to shear substantially in the interface.

(2) An oxide that "rubs off" readily, but not faster than it regrows, can be formed. The rate of growth will depend on the thickness, the availability of oxygen and the temperature of the surface region. The crucial partial pressure of oxygen could be controlled to vary according to the oxides that we wish to form. For example, in $\mathrm{Fe}_{2} \mathrm{O}_{3}$ and $\mathrm{Fe}_{3} \mathrm{O}_{4}$ (n-type semiconductors in which vacancies transfer predominates) oxygen ions travel fast through the oxide forming new oxide at the interface between the oxide and the metal. In contrast, $\mathrm{FeO}$ (a p-type semiconductor in which electrons transfer readily) iron ions travel quickly through the oxide to form new FeO on the interface with air.

Furthermore, the removed oxide should not be abrasive. Thus, for example, $\mathrm{Fe}_{2} \mathrm{O}_{3}$ (which is a hard rhombohedral hematite and forms at temperatures below $300{ }^{\circ} \mathrm{C}$ ) should be avoided in favor of $\mathrm{Fe}_{3} \mathrm{O}_{4}$ (a more ductile spinel magnetite which forms at temperatures above $300{ }^{\circ} \mathrm{C}$ ) or $\mathrm{FeO}$ (a soft wüstite which is unstable below $570{ }^{\circ} \mathrm{C}$ ).

(3) Very small areas of the oxide can be allowed to "flake off" from the substrate in areas of great distress, which would quickly decrease the height of dangerous asperities. The oxide then should not attach very tenaciously to the substrate, and it should not detach as large flakes. It is interesting that chromium oxide and aluminum oxide are tenacious, and this may explain why stainless steel and aluminum alloys are very scuff prone. To give a perspective on the tenacity of oxides, some tests were done by sliding various polymers over $440 \mathrm{C}$ stainless steel. It was found that the polymers that had a shear strength less than $9200 \mathrm{lbf}^{-2}(63.4 \mathrm{MPa})$ did not remove oxide from the stainless steel, whereas polymers with a shear strength over $9500 \mathrm{lbf}^{-2}(65.5 \mathrm{MPa})$ did remove oxide from stainless steel [64]. It would, therefore, seem that the tenacity or shear strength of oxide on stainless steel is of the order of $9500 \mathrm{lbf} \mathrm{in}^{-2}(65.5 \mathrm{MPa})$ and perhaps this property should be the focus of research attention rather than the properties of the substrates.

All the above implies that methods should be developed to measure the thickness, mechanical properties and chemical composition of thin films on sliding surfaces, preferably in situ. 


\section{The properties and deformation of asperities}

It seems obvious that, if the deformation of asperities is to be studied, it would be well to know their shapes and properties. Several papers are available in which idcal aspcrity shapes are described [65-71] and more are available in which the plastic deformation of asperities is reported [72 - 77]. In some of these papers two surfaces are "pressed together" in order to determine the influence of applied load on real contact area.

The response of asperities to combined stresses should be studied. In particular, the added influence of oxide layers should be considered, and the influence of the overlapping of strain fields around individual asperities should be studied.

Few published papers have been able to explain the two observations noted earlier in the present paper. These are, that two-phase materials appear to resist scuffing much better than do single-phase materials, and that two surfaces may have the same numerical value of the surface roughness but perform very differently in lubricated sliding. Thus further surface studies should include the basic mechanisms of surface formation in the processes, and they should also focus on the role of multiple phases in the total condition of the finished surface. The deformation of asperities during sliding could then be studied on a realistic basis. It would, of course, be much more difficult than if one assumes ideal materials and asperity shapes. However, the advice of $\mathrm{Ku}$ would be more nearly followed if real asperities were studied.

\section{References}

1 Research Group on Wear of Engineering Materials of the European Organisation for Economic Co-operation and Development, Glossary of Terms and Definitions in the Field of Friction, Wear and Lubrication, Organisation for Economic Co-operation and Development, Paris, 1969, p. 53.

2 G. Salomon, Failure criteria in thin film lubrication - the IRG program, Wear, 36 (1976) 1 - 6 .

$3 \mathrm{H}$. Czichos, Failure criteria in thin film lubrication: investigation of the different stages of film failure, Wear, 36 (1976) 13.

4 G. Bollani, Failure criteria in thin film lubrication with EP additives, Wear, 36 (1976) $19 \cdot 23$.

5 P. M. Ku, Gear failure modes - importance of lubrication and mechanism, ASLE Trans., 19 (1976) 239.

6 A. Dyson, Scuffing - a review, Parts 1 and 2, Tribol, Int., 8 (April 1975) 77;8 (June 1975) 117 .

7 D. Scott, A. I. Smith, S. Tait and G. R. Tremain, Materials and metallurgical aspects of piston ring scuffing - a literature survey, Wear, 33 (1975) 293.

$8 \mathrm{M}$. J. Neale, Piston ring scuffing - a broad survey of problems and practice, Proc. Inst. Mech. Eng., London, 185 (1970 - 1971) 21.

9 M. D. Rogers, The mechanism of scuffing in diesel engines, Wear, 15 (1970) 105 116.

10 R. G. Bayer and J. L. Sirico, The influence of surface roughness on wear, Wear, 35 (1975) $251-260$. 
11 W. Hirst and A. E. Hollander, Surface finish and damage in sliding, Proc. $R$. Soc. London, Ser. A, 337 (1974) 379 - 394.

12 A. Dyson, The failure of elastohydrodynamic lubrication of circumferentially ground discs, Proc., Inst. Mech. Eng., London, 190 (52/76) (1975 - 1976) 699.

13 A. W. Crook and B. A. Shotter, Some scuffing experiments in a disc machine, Proc. Lubrication and Wear Conf., October, 1957, Institution of Mechanical Engineers, London, 1958, Paper 6.

14 P. B. MacPherson and A. Cameron, Scoring: a new form of lubricant failure, ASLE Trans., $16(1973) 68-72$.

15 A. Ura, The relationship between some tribofailures and surface roughness. In N. P. Suh and N. Saka (eds.), Fundamentals of Tribology, Massachusetts Institute of Technology Press, Cambridge, MA, 1980.

16 T. E. Tallian, Rolling bearing life modifying factors for film thickness, surface roughness, and friction, J. Lubr. Technol., 103 (1981) 531.

17 J. C. Bell, A. Dyson and J. W. Hadley, The effects of rolling and sliding speeds on the scuffing of lubricated steel discs, ASLE Trans., 18 (1975) 62 - 73.

18 A. Begelinger and A. W. J. de Gee, Failure of thin film lubrication - the effect of running-in on the load carrying capacity of thin-film lubricated concentrated contacts, J. Lubr. Technol., 103 (1981) 203.

19 K. J. Stout, T. G. King and D. J. Whitehouse, Analytical techniques in surface topography and their application to a running-in experiment, Wear, 43 (1977) $99-115$.

20 G. W. Rowe, Surface topographic changes at breakdown of thin-film lubrication; a short account of a collaborative C.I.R.P. investigation, Wear, 28 (1974) 125 - 130.

21 G. Masouros, A. Dimarogonas and K. Lefas, A model for wear and surface roughness transients during the running-in of bearings, Wear, 45 (1977) $375-382$.

22 S. C. Kang and K. C. Ludema, Oxide film growth and loss in lubricated sliding, Int. Conf. on Wear of Materials, Vancouver, April 1985, to be published.

23 R. S. Montgomery, Run-in and glaze formation on gray cast iron surfaces, Wear, 14 (1969) 99 .

24 A. V. Sreenath and N. Raman, Mechanism of smoothing of cylinder liner surface during running-in, Tribol. Int., 9 (April 1976) 55.

25 S. Singhal, Asperity welding - an aspect of scuffing of a lubricated sliding contact, Wear, 24 (1973) 391 - 394.

26 H. S. Cheng, personal communication, 1982.

27 F. P. Bowden and D. Tabor, Friction and Lubrication of Solids, Clarendon, Oxford, 1954

28 F. G. Rounds, Additive interactions and their effect on the performance of a zinc dialkyl dithiophosphate, ASLE Trans., 21 (1978) 91.

29 A. C. Base, E. E. Klaus and E. J. Tewksbury, Evaluation of wear products produced by some chemical reactions in boundary lubrication, ASLE Trans., 19 (1976) 287 292.

30 A. Dyson, Scuffing, Treatise Mater. Sci. Technol., 13 (1979) 195.

$31 \mathrm{H}$. Czichos, Failure criteria in thin film lubrication - the concept of a failure surface, Tribol. Int., 7 (February 1974) 14.

32 F. T. Barwell and A. A. Milne, Criteria governing scuffing failure, J. Inst. Pet., 38 (1952) 624.

$33 \mathrm{~J}$. Föhl and H. Uetz, Failure criteria in thin film lubrication - influence of temperature on seizing, wear and reaction layer formation, Wear, 36 (1976) $25-32$.

$34 \mathrm{M}$. Ibrahim and A. Cameron, Oil film thickness and the mechanism of scuffing in gear teeth, Proc. Lubrication and Wear Conv., May 1963, Institution of Mechanical Engineers, London, 1963, p. 228.

35 W. Hirst, Scuffing and its prevention, Chart. Mech. Eng., (1974) 88.

36 A. Begelinger and $A$. W. J. de Gee, On the mechanism of lubricant film failure in sliding concentrated steel contacts, J. Lubr. Technol., 98 (1976) 575.

$37 \mathrm{H}$. Christensen, Failure by collapse of hydrodynamic oil films, Wear, 22 (1972) 359. 
38 W. Hirst and J. V. Stafford, Transition temperatures in boundary lubrication, Proc., Inst. Mech. Eng., London, 186 (1972) 179.

$39 \mathrm{H}$. A. Spikes and A. Cameron, Scuffing as a desorption process - an explanation of the Borsoff effect, ASLE Trans., 17 (1974) 92 - 96.

40 D. B. Durkee and H. S. Cheng, An examination of a possible mode of scuffing failure in simple sllding, Wear, 59 (1980) $223-230$.

41 R. A. Burton, Thermomechanical effects in sliding wear, Rep., March 7, 1978 (Northwestern University, IL).

42 F. Hirano and Y. Yamamoto, Effect of molecular weight distribution of mineral oils on scuffing under rolling/sliding conditions, Conf. on Tribology, Swansea, April 3 - 4, 1978, Paper C29/78.

43 Q. J. Xue and K. C. Ludema, Plastic failure effects in scuffing of soft metals, Proc. Int. Conf. on Wear of Materials, Reston, VA, 1983, American Society of Mechanical Engineers, New York, 1983, p. 499.

44 B. B. Baber, E. L. Anderson and P. M. Ku, Effect of lubricant, metals, temperature, and atmospheric environments on gear load-carrying capacity, J. Lubr. Technol., 90 (1968) 117 - 124 .

45 I. B. Goldman, J. K. Appeldoorn and F. F. Tao, Scuffing as influenced by oxygen and moisture, ASLE-ASME Lubrication Conf., Houston, TX, October 1969.

46 R. S. Fein and K. L. Kreuz, Chemistry of boundary lubrication of steel by hydrocarbons, ASLE Trans., 8 (1965) 29 - 38.

47 A. Cameron, The role of surface chemistry in lubrication and scuffing, ASLE Trans., 23 (1980) 388 - 392.

48 W. R. Jones, Ferrographic analysis of wear debris from boundary lubrication experiments with a five ring polyphenyl ether, ASLE Trans., 18 (1975) $153 \cdot 162$.

49 R. O. Bjerk, Oxygen - an 'extreme-pressure agent', ASLE Trans., 16 (1973) 97 - 106.

$50 \mathrm{M}$. Tomaru, S. Hironaka and T. Sakurai, Effects of oxygen on the load-carrying action of some additives, Wear, 41 (1977) $117-140$.

51 A. Begelinger and A. W. J. de Gee, On the mechanism of lubricant film failure in sliding concentrated steel contacts, J. Lubr. Technol., 98 (1976) 575.

52 A. Begelinger and A. W. J. de Gee, Boundary lubrication of sliding concentrated steel contacts, Wear, 22 (1972) 337.

53 F. P. Bowden and D. Tabor, Friction and Lubrication of Solids, Vol. II, Clarendon, Oxford, 1964, pp. 49 - 51.

$54 \mathrm{~W}$. Hirst and J, K. Lancaster, Surface film formation and metallic wear, J. Appl. Phys., 27 (1956) 1057.

$55 \mathrm{~J}$. K. Lancaster, The formation of surface films at the transition between mild and severe metallic wear, Proc. R. Soc. London, Ser. A, 273 (1963) 466.

56 R. T. Spurr, The behaviour of films on sliding surfaces, Wear, 7 (1964) 551 - 557.

57 R. Wilson, Influence of oxide films on metallic friction, Part I, Friction of metals, Proc. R. Soc. London, Ser. A, 212 (1952) 450.

58 S. W. E. Earles and D. G. Powell, Stability of self-generated oxide films on unlubricated En. 1A steel surfaces, Proc., Inst. Mech. Eng., London, 182 (3N) (1967-1968) 167.

59 N. Tenwick and S. W. E. Earles, A simplified theory for the oxidative wear of steels, Wear, 18 (1971) 381 - 391.

60 J. Mфlgaard, A discussion of oxidation, oxide thickness and oxide transfer in wear, Wear, 40 (1976) $277-291$.

61 F. H. Stott and G. C. Wood, Friction and wear of alloys, Tribol. Int., 11 (1978) 211.

62 J. E. Wilson, F. H. Stott and G. C. Wood, The development of wear-protective oxides and their influence on sliding friction, Proc. R. Soc. London, Ser. A, 369 (1980) 557 574.

63 O. Kubaszewski and B. E. Hopkins, Oxidation of Metals and Alloys, Butterworths, London, 1962. 
64 S. H. Rhee and K. C. Ludema, Mechanisms of formation of polymeric transfer films, Wear, 46 (1978) 231.

$65 \mathrm{~K}$. A. Nuri, Some factors influencing the contact behavior of surfaces, $J$. Lubr. Technol., $102(1980) 15$.

$66 \mathrm{~J}$. A. Greenwood and J. B. P. Williamson, Contact of nominally flat surfaces, Proc. $R$. Soc. London, Ser. A, 295 (1966) 300.

$67 \mathrm{H}$. Czichos, Influence of asperity contact conditions on the failure of sliding elastohydrodynamic contacts, Wear, 41 (1977) $1-14$.

$68 \mathrm{~K}$. Fujiwara, A method of observing the area of contact and the mechanical breakdown of a surface film, Wear, 50 (1978) $275-284$.

69 T. Sakamoto and T. Tsukizoe, Metal transfer in the frictional contact of a rough hard surface, Wear, 47 (1978) $301 \cdot 313$.

70 H. S. Nagaraj, D. M. Sanborn and W. O. Winer, Asperity interactions in EHD contacts, J. Lubr. Technol., 100 (1978) 246.

$71 \mathrm{M}$. Kaneta and A. Cameron, Effects of asperities in elastohydrodynamic lubrication, J. Lubr. Technol., 102 (1980) 374.

72 R. D. Arnell, A. P. Herod and D. G. Teer, The effect of combined stresses on the transition from mild to severe wear, Wear, 31 (1975) 237.

73 K. L. Johnson, J. A. Greenwood and S. Poon, A simple theory of asperity contact in elastohydrodynamic lubrication, Wear, 19 (1972) $91-108$.

74 J. M. Challen and P. L. B. Oxley, An explanation of the different regimes of friction and wear using asperity deformation models, Wear, 53 (1979) $229-243$.

75 I-M. Feng, Plastic roughening and wear, Proc. Lubrication and Wear Conf., October 1957, Institution of Mechanical Engineers, London, 1958, p. 33.

76 J. H. Dautzenberg and J. H. Zaat, Quantitative determination of deformation by sliding wear, Wear, 23 (1973) 9 - 19.

$77 \mathrm{~W}$. R. D. Wilson, Workpiece surface roughening in a hydrodynamically lubricated metal forming process, J. Lubr. Technol., 100 (1978) 10. 